\title{
Exploring the mechanisms of graphene oxide behavioral and morphological changes in zebrafish
}

\author{
Zaira Clemente $^{1,2}$ (1) $\cdot$ Gabriela Helena Silva ${ }^{1,2,3} \cdot$ Miriam Celi de Souza Nunes ${ }^{4}$. Diego Stéfani Teodoro Martinez ${ }^{2,3}$. \\ Claudia Vianna Maurer-Morelli ${ }^{4} \cdot$ Andre Alexandre Thomaz $^{5,6} \cdot$ Vera Lúcia Scherholz Salgado Castro $^{1}$
}

Received: 12 March 2019 / Accepted: 28 June 2019 / Published online: 28 August 2019

(C) Springer-Verlag GmbH Germany, part of Springer Nature 2019

\begin{abstract}
The presence of natural organic matter such as humic acid (HA) can influence the behavior of graphene oxide (GO) in the aquatic environment. In this study, zebrafish embryos were analyzed after 5 and 7 days of exposure to $\mathrm{GO}\left(100 \mathrm{mg} \mathrm{L}^{-1}\right)$ and $\mathrm{HA}(20 \mathrm{mg}$ $\mathrm{L}^{-1}$ ) alone or together. The results indicated that, regardless of the presence of HA, larvae exposed to GO for 5 days showed an increase in locomotor activity, reduction in the yolk sac size, and total length and inhibition of AChE activity, but there was no difference in enzyme expression. The statistical analysis indicated that the reductions in total larval length, yolk sac size, and AChE activity in larvae exposed to GO persisted in relation to the control group, but there was a recovery of these parameters in groups also exposed to HA. Larvae exposed to GO for 7 days did not show significant differences in locomotor activity, but the RT-PCR gene expression analysis evidenced an increase in the AChE expression. Since the embryos exposed to GO showed a reduction in overall length, they were submitted to confocal microscopy and their muscle tissue configuration investigated. No changes were observed in the muscle tissue. The results indicated that HA is associated with the toxicity risk modulation by GO and that some compensatory homeostasis mechanisms may be involved in the developmental effects observed in zebrafish.
\end{abstract}

Keywords Graphene oxide $\cdot$ Biomarker $\cdot$ Ecotoxicology $\cdot$ Humic acid $\cdot$ Zebrafish

\section{Introduction}

There is still a need to fill the knowledge gaps between nanotoxicological research and nanomaterial safety. Various physicochemical properties of nanomaterials (NM) and numerous abiotic factors influence the ecotoxicity of nanomaterials, both spatially and with time. The aquatic

Responsible editor: Philippe Garrigues

Electronic supplementary material The online version of this article (https://doi.org/10.1007/s11356-019-05870-z) contains supplementary material, which is available to authorized users.

Zaira Clemente

zairaclemente@hotmail.com

1 Laboratory of Ecotoxicology and Biosafety, Embrapa Environment, Jaguariúna, São Paulo 13820-000, Brazil

2 Brazilian National Nanotechnology Laboratory (LNNano), Brazilian Center for Research on Energy and Materials (CNPEM),

Campinas, São Paulo 13083-970, Brazil

3 Center for Nuclear Energy in Agriculture (CENA), University of São Paulo (USP), Piracicaba, São Paulo 13416-000, Brazil environment is of particular interest since it tends to be the ultimate sink for particulate contaminants. NM can be carried from emission sources towards aquatic environments via various routes, including the atmosphere, surface leaching, municipal wastewater treatment plants, and water purification activities. Entrance pathways of carbon nanomaterials into aquatic systems include direct inputs, through the sewage
4 Department of Medical Genetics, School of Medical Sciences, University of Campinas (UNICAMP), Campinas, São Paulo 13087-883, Brazil

5 Department of Quantum Electronics, Institute of Physics "Gleb Wataghin”, University of Campinas (UNICAMP), Campinas, São Paulo 13083-859, Brazil

6 National Institute of Photonics Applied to Cell Biology (INFABIC), University of Campinas (UNICAMP), Campinas, São Paulo 13083-859, Brazil 
and water effluents, as well as indirect inputs, associated with run-off events or atmospheric depositions (Freixa et al. 2018). The increasing environmental concentrations (Markovic et al. 2018; Mottier et al. 2017; Pecoraro et al. 2018) underline the need for studies of the environmental fate of carbon nanomaterials dispersed in water.

Once in the aquatic environment, NM are highly affected by their surroundings and consequently undergo transformations (Ivask et al. 2014). Their toxic effects essentially depend on several factors such as the formation of aggregates, the exposure route, dose-response, exposure time, the response of the receptor organisms, and the interactions in the mechanisms involved in the physiological uptake process (Pecoraro et al. 2018). Thus, for example, the fate of graphene oxide (GO) can be affected by the $\mathrm{pH}$ and by divalent cations such as $\mathrm{Ca}^{+2}$, whose presence in the medium promoted less stability (Chowdhury et al. 2015; Lanphere et al. 2014; Yang et al. 2016; Wu et al. 2013). The last decade of research showed that NM had the ability to act via multiple pathways apart from oxidative stress (Bundschuh et al. 2018).

The behavior of NMs in the aquatic environment varies considerably depending on the environmental conditions. The natural organic matter, which spreads throughout aquatic systems, has a mass concentration of dissolved organic carbon ranging from 0.5 to $100 \mathrm{mg} / \mathrm{L}$ (Spencer et al. 2012). Humic acid (HA), the main existing form of NOMs (natural organic matters), can interact extensively with various engineered nanoparticles to improve their stability in aqueous solutions (Pradhan et al. 2018). The potential contamination of a river or lake by NM can be mitigated by an abundancy of HA (Kteeba et al. 2017) since it contains many hydrophilic groups that show excellent ability to adjust the behaviors and toxicities of NM in the environment (Zhang et al. 2016). Indeed, some studies have shown that the presence of HA in the exposure medium alters the toxicity of the NMs (Dasari and Hwang 2013; Deng et al. 2016; Hu et al. 2011; Kim et al. 2013; Yang et al. 2011).

GO nanoparticles may undergo complicated environmental behaviors (dispersion, aggregation, transformation, adsorption, or sedimentation) after being released into water bodies (Wang et al. 2018). NOMs can reduce GO aggregation even under relatively high ionic strength conditions. Hydrogen bonding, $\pi-\pi$ interactions and Lewis acid-base interaction have been suggested as the principal mechanisms contributing to GO interactions with HA (Wang et al. 2018). Thus, it is important to examine the effects of GO on non-target organisms in the presence of different environmental factors such as $\mathrm{HA}$ at relevant environmental concentrations in order to understand the potential risks of GO.

Castro et al. (2018) showed that the presence of HA changed the toxic effects of $\mathrm{GO}$ on aquatic organisms. In particular, with respect to the exposure of zebrafish embryo to GO, although it showed no acute toxicity or malformation, the larvae showed reductions in overall length and in their acetylcholinesterase (AChE) activity. In the presence of HA, the acid phosphatase activity was also inhibited (Clemente et al. 2017).

AChE activity is necessary for the correct development of the muscles and protection against damage in the subsequent stages (Behra et al. 2002). In addition to the neuromuscular function, it has been shown that $\mathrm{AChE}$ is responsible for several roles during development (Drews 1975; Soreq and Seidman 2001). In particular, the morphometric developmental delay parameters in zebrafish embryos have a moderate correlation with AChE activity, which is a sensitive marker of developmental delay in the absence of malformation (Teixidó et al. 2013).

However, GO neurotoxicity is still under investigation since it can lead to some in vitro effects on neuronal transmission and functionality, such as inhibition in excitatory transmission, a reduction in the number of excitatory synaptic contacts, and a concomitant increase in inhibitory activity (Bramini et al. 2016). Considering that Clemente et al. (2017) observed in vivo but not in vitro AChE inhibition, it may be possible that there are some non-direct interactions between the NM and the enzyme. Such interactions need to be investigated since morphological and biochemical changes may be related to behavioral abnormalities and affect the survival of the organism, leading to environmental consequences.

In order to better evaluate larval size reduction and $\mathrm{AChE}$ activity inhibition by GO in the absence and presence of HA, this work investigated behavioral and morphological (muscular development) parameters and the AChE expression in zebrafish larvae exposed to this NM.

\section{Materials and Methods}

\section{Materials - graphene oxide and humic acid}

In order to carry out this study, single layer graphene oxide (GO, batch MKBV1192V, code 763713) and the sodium salt of humic acid (HA) (batch STBCS468V, code H16752, technical grade, CAS number 1415-93-6), both from Sigma Aldrich, were used.

\section{Physicochemical characterization of graphene oxide}

The GO sample used in this work was well characterized, as described by Castro et al. (2018). Briefly, the flake size of the GO ranged from 50 to $650 \mathrm{~nm}$, with a mean value of $225 \pm$ $105 \mathrm{~nm}$ (atomic force microscopy (AFM-Digital Instruments Nanoscope III, Vecco Instruments).

The GO surface chemistry was chemically analyzed using X-ray photoelectron spectroscopy (XPS-K-Alpha XPS, Thermo Scientific), showing the following chemical groups 
(\% atomic): graphitic/aromatic carbon $(3.7 \%)$, aliphatic carbon $(39.8 \%)$, epoxy/carboxyl/ester $(7.5 \%)$. X-ray diffraction (DRX-Shimadzu, Model XDR7000) and the thermogravimetric analysis (TGA, NETZSCH, STA449 F3 Jupiter thermo analyzer) demonstrated the exfoliation of the graphite and generation of a single layer of graphene oxide. Raman spectroscopy was used to characterize the structural defects of the GO sample, with an ID/IG value of 1.04 (Raman Confocal Microscope, Witec Model Apha300).

\section{Dispersion stability of graphene oxide in the presence and absence of humic acid}

A stock dispersion of GO was prepared and used for all the dispersion stability and toxicity studies in this work. Twenty milligrams of GO was dispersed in a $20 \mathrm{~mL}$ of ultrapure water and sonicated for $30 \mathrm{~min}$ in an ultrasound bath (Cole-Parmer, Mod. 8891). The HA stock solution (20 mg/L) was prepared in a culture medium of zebrafish embryos.

The stabilities of the $\mathrm{GO}\left(1,10\right.$, and $\left.100 \mathrm{mg} \mathrm{L}^{-1}\right)$ and HA (20 $\mathrm{mg} \mathrm{L}^{-1}$ ) dispersions in the different culture media were monitored by spectrophotometry with and without HA without changes in solutions (Clemente et al. 2017). The NOM levels found in most natural waters range from 0.1 to $20 \mathrm{mg} / \mathrm{L}$ (Rodrigues et al. 2009) and the presence of NOM has been reported to influence on the fate and transport of nanomaterials (De Marchi et al. 2018a). The HA concentration used in this work was based on the literature (Botero et al. 2011; Clemente et al. 2017; OECD 2000) since it is representative of those found in typical surface and groundwaters (Batley et al. 2013; Li et al. 2009; Wang et al. 2015a). More than that, HA in a concentration of $20 \mathrm{mg} / \mathrm{L}$ (realistic for surface waters) was able to disperse NPs during periods of $24 \mathrm{~h}$ or more (Pradhan et al. 2018).

As fate and effect studies are generally performed in laboratory settings, mimicking to a varying extent realistic exposure conditions is important for the detailed understanding of the processes controlling the fate and behavior of nanomaterials. Thus, investigations should be made in environmental conditions to obtain an improved knowledge of their transformation/dissolution and mobility in different aquatic settings (Peijnenburg et al. 2015). Although the tested concentrations of GO $100 \mathrm{mg} \mathrm{L}^{-1}$ is higher than environmentally relevant concentrations at present (Freixa et al. 2018), since the objective of the work is to analyze the mechanisms of toxicity of GO, it was chosen a high concentration because below its no effects are commonly observed.

\section{Bioassays-mortality or malformation}

Zebrafish (Danio rerio, wild type) embryos were kept in reconstituted water prepared as the moderately hard water described by USEPA (2002). The characteristics of the water used for the embryo exposures were $96 \mathrm{mg} \mathrm{L}^{-1} \mathrm{NaHCO}_{3}, 60$ $\mathrm{mg} / \mathrm{L} \mathrm{MgSO}_{4}, 4 \mathrm{mg} \mathrm{L}^{-1} \mathrm{KCl}, 60 \mathrm{mg} \mathrm{L}{ }^{-1} \mathrm{CaSO}_{4} \cdot 2 \mathrm{H}_{2} \mathrm{O}, \mathrm{pH}$ $7.0 \pm 0.5$, conductivity $350 \pm 100 \mathrm{~ms} \mathrm{~cm}^{-1}$, and temperature $27.0 \pm 1{ }^{\circ} \mathrm{C}$. Embryos, $4 \mathrm{~h}$ postfertilization (hpf), were exposed to graphene oxide forming the following groups: 0 (control), $20 \mathrm{mg} \mathrm{L}^{-1} \mathrm{HA}, 100 \mathrm{mg} \mathrm{L}^{-1} \mathrm{GO}$, and $100 \mathrm{mg} \mathrm{L}^{-1}$ $\mathrm{GO}+20 \mathrm{mg} \mathrm{L}^{-1} \mathrm{HA}$. The exposure was continued for 5 or 7 days in polystyrene Petri dishes (maintaining the ratio of 60 embryos in 50-mL suspension) with a light/dark cycle of $14 /$ $10 \mathrm{~h}$ at $26 \pm 1{ }^{\circ} \mathrm{C}$.

This exposure period covered the embryonic and larval stage since hatching and major developmental processes of zebrafish occur during the first 3 days postfertilization (dpf), and the major organs of zebrafish larvae are developed within 5-6 dpf (Zhang et al. 2017).

Other carbon nanomaterials as nanotubes have low mobility and bioavailability in aquatic ecosystems, whereas high persistence in sediment (Schierz et al. 2014). Carbon nanomaterials as nanotubes at $120 \mathrm{mg} / \mathrm{L}$ (Cheng et al. 2007) and $\mathrm{GO}$ at $100 \mathrm{mg} / \mathrm{L}$ (Chen et al. 2016a) can adhere in chorion membrane, blocked the pore canals of the chorionic membrane, and caused marked hypoxia and hatching delay.

Thus, in order to examine the effects that could occur after an exposition to GO in the presence of HA as observed by Clemente et al. (2017), the exposure medium of all groups was renewed only on the 4 days postfertilization (dpf) to provide a more oxygenated medium for the embryos.

The organisms were evaluated every $24 \mathrm{~h}$ regarding the occurrence of mortality or malformation. At the end of the fifth and seventh days of exposure, live larvae were photographed using $\times 2$ magnification for measurement of their total length and yolk sac width by way of the Optika View Version 7.1.1.5 software, previously calibrated for a millimeter scale.

The experimental procedures used in this study were previously approved by the Embrapa Environment Ethics Commission (CEUA-Embrapa Meio Ambiente, protocol 002/2014) and the Institute of Biology of Unicamp (CEUAIB, protocol 4333-1).

The larvae used in the morphological and behavioral tests were from the same batch. After the behavioral tests, the larvae were fixed for later analysis by stereomicroscopy and confocal microscopy (size and somite measurements). The larvae collected for enzymatic analysis and PCR were immediately washed and frozen (6-7 larvae for each purpose), and the results normalized as milligram of protein for $\mathrm{AChE}$ and as milligram of RNA for PCR.

\section{Preparation of fluorescein-labeled graphene oxide}

Fluorescein isothiocyanate-coated graphene oxide (FTIC$\mathrm{GO}$ ) was prepared and used to evaluate $\mathrm{GO}$ penetration into the embryo as described by Cheng et al. (2015), and 
preliminary tests were carried out to establish the best preparation conditions. The final sample, for use in the bioassay, was prepared by mixing $5 \mathrm{~mL}$ of the solution OG 1 g.L $\mathrm{L}^{-1}, 50$ $\mu \mathrm{L}$ of the solution FITC 1 g. $\mathrm{L}^{-1}$, e $5 \mathrm{~mL}$ of ultrapure water. The mixture was incubated for $20 \mathrm{~min}$ in the dark, sonicated for $4 \mathrm{~min}$, and then dialyzed to remove the free FTIC (Inlab 133 membrane, 24-porosity). Dialysis was carried out for approximately $4 \mathrm{~h}$, with periodic changes of the dialysis water and monitoring of the fluorescence emission (Shimadzu RF$5301 \mathrm{PC}, \lambda$ excitation $=498 \mathrm{~nm}, \lambda$ emission $=516 \mathrm{~nm})$. The fluorescence of the dialysis water fell from 5.3 to 0.09 at the end of the period. The labeling of the GO-FTIC sample was confirmed by spectrofluorimetry (Shimadzu RF-5301 PC, $\lambda$ excitation $=498 \mathrm{~nm}, \lambda$ emission $=516 \mathrm{~nm}$ ) and fluorescence microscopy. The fluorescence of the GO-FTIC samples was monitored and shown to be stable for up to 4 days after preparation.

\section{Penetration of GO in the embryos}

Two hours after fertilization, 5 embryos were incubated with the GO-FTIC solutions (1, 10, and $\left.100 \mathrm{mg} \mathrm{L}^{-1}\right)$ with or without HA (20 mg L $\left.{ }^{-1}\right)$ for $24 \mathrm{~h}$ in the dark at $27 \pm 1{ }^{\circ} \mathrm{C}$, and then analyzed by confocal microscopy (Zeiss Inverted Microscope LSM 780 objective EC Plan Neofluoar $\times 20 / 0.50$ M27, $\lambda$ excitation $=488 \mathrm{~nm}, \lambda$ emission $=559 \mathrm{~nm}$ ). Since it was not possible to exclude technical artifacts (see "Results and discussion"), this test was not performed at later stages of the zebrafish.

\section{Behavioral analysis}

Under laboratory conditions $\left(28.5^{\circ} \mathrm{C}\right)$, zebrafish larvae typically hatch 2 to $3 \mathrm{dpf}$. After hatching, they adhere to hard surfaces through specialized cells present in the head, performing very little spontaneous swimming activity until $5 \mathrm{dpf}$, when they inflate their swimming bladders (Lawrence 2007).

To investigate the swimming behavior in the different groups, the zebrafish larvae were individually placed in 96well culture plates with a final volume of $100 \mu \mathrm{L}$ of reconstituted water at $27 \pm 1{ }^{\circ} \mathrm{C}$ and allowed a period of adaptation to the environment of $30 \mathrm{~min}$ before image capture. The larvae were previously placed in clean reconstituted water to eliminate possible residues of GO and HA. The behavioral analysis was carried out in the light period, which is the period of greater activity of the animals. The distribution of the animals on the experimental plate was done in a semirandomized way with the purpose of having representatives of each group in all the lines and columns of the microplate, reducing the possibility of biases. Each experimental group was composed of $n=12$. The DanioVision system (Noldus, Wageningen, The Netherlands) was used for the behavioral analysis. The behavior (speed, distance traveled, and time in motion) was monitored for $30 \mathrm{~min}$ and quantified using the EthoVision XT software (Noldus, Wageningen, The Netherlands). The organisms were evaluated at $120 \mathrm{hpf}$ (5 days) and 168 hpf (7 days).

\section{Analysis of acetylcholinesterase activity}

At the end of the fifth and seventh days of exposure, the live larvae were washed in phosphate buffer $\left(0.5 \mathrm{~mol} \mathrm{~L}^{-1}, \mathrm{pH} 7\right)$ and frozen at $-80^{\circ} \mathrm{C}$ in Eppendorf type microtubes, maintaining the ratio of 7 larvae to $0.5 \mathrm{~mL}$ of buffer. The samples were homogenized using an ultra-turrax (IKA, China) and then centrifuged $\left(10 \mathrm{~min}, 10,000 \times g, 4{ }^{\circ} \mathrm{C}\right)$. The supernatant was used for the analysis of acetylcholinesterase activity (AChE) and protein concentration. Five pools of larvae were analyzed for each group, and all readings were carried out in triplicate. The analyses were carried out in a microplate reader (Tecan Sunrise), determining the protein concentration by the Bradford method (1976) and the AChE activity according to the Ellman method (1961), modified for microplate use: 15 $\mu \mathrm{L}$ of homogenate was added to $15 \mu \mathrm{L}$ of $9 \mathrm{mmol} \mathrm{L}^{-1}$ acetylthiocholine and $70 \mu \mathrm{L}$ of 5,5-dithio bis-2nitrobenzoate (DTNB) $0.75 \mathrm{mmol} \mathrm{L}^{-1}$. The absorbance was monitored for $5 \mathrm{~min}$ at $415 \mathrm{~nm}, 30^{\circ} \mathrm{C}$.

\section{Extraction of RNA and qPCR}

At the end of the exposure period (5 and 7 days), the larvae were cryoanesthetized and sacrificed by deepening the anesthesia and rapidly freezing in liquid nitrogen. For the total RNA extraction, each sample was composed of a pool of 6 larvae ( $n=6-7$ pools/group). The total RNA was extracted using the conventional TRIzol® protocol (Invitrogen, Carlsbad, CA, USA), and its concentration and quality determined using an EpochTM spectrophotometer (BioTek, Winooski, VT, USA) and agarose gel electrophoresis, respectively. For the reverse transcription step, $1 \mu \mathrm{g}$ of total RNA was used by using high capacity (Invitrogen, Carlsbad, CA, USA). Reactions without RNA were used as the negative control. Real-time PCR was carried out using the TaqMan System composed of TaqMan ${ }^{\circledR}$ Universal Master Mix and TaqMan ${ }^{\circledR}$ Gene Expression Assay (Invitrogen, Carlsbad, CA, USA). The PCR was done using the real-time PCR 7500 equipment and the data analysis using the SDS 7500 software (Applied Biosystems, Foster City, CA, USA). A specific assay for zebrafish (Dr03093481-m1 Applied Biosystems) was used for the target gene analysis (acetylcholinesterase) and all quantifications were carried out in triplicate and normalized with the endogenous eefla111 control (McCurley and Callard 2008; Tang et al. 2007). To test the efficiency of the PCR reactions, standard curves were calculated using the formula $E=10$ (-1/slope). The relative quantification (RQ) was calculated from the equation $\mathrm{RQ}=2-\Delta \Delta \mathrm{CT}$, described by Livak 
and Schmittgen (2001). Each plate analyzed contained a cDNA-free sample in order to compose a negative control of the reactions.

\section{Morphological muscle analyses}

After the exposure period to the experimental conditions, the larvae were fixed in $4 \%$ paraformaldehyde (overnight) and depigmented by incubation for $10 \mathrm{~min}$ in a solution containing $3 \%$ hydrogen peroxide and $1 \%$ potassium hydroxide. The larvae were then washed and maintained in PBS buffer $\mathrm{pH} 7$ until analyzed. The larvae muscle tissue was analyzed by confocal microscopy (Zeiss Inverted Microscope LSM $780 \times 40$ oil immersion objective, N.A. 1.3), using the second harmonic generation technique (SHG). A pulsed femtosecond laser (Mai Tai HP Spectra Physics, $\sim 100 \mathrm{fs}, 80 \mathrm{MHz}$ ) was used as the excitation source at $800 \mathrm{~nm}$ and a 415 -nm short-pass filter selected the backscattered SHG signal. Images were obtained from the somites near the tail (somites 20-24) (Huang et al. 2011), taking images of at least 10 larvae per group and measuring the width of 8 somites/larvae (Fig. 1). The sarcomere width was measured as described by Huang et al. (2011) analyzing images of 5 larvae/group. At least 20 measurements were taken of the sarcomere of each larva.

\section{Statistical analysis}

The data were analyzed by two-way ANOVA (considering the factors of graphene oxide and humic acid) followed by the Bonferroni test after a significant ANOVA. The significance of the data was accepted when $p<0.05$.
The data were presented as the mean values \pm SEM. The statistical analysis was carried out using the GraphPad Prism version 5.0 for all analyses (GraphPad Software, San Diego, CA, USA).

\section{Results and discussion}

\section{Physicochemical characterization of graphene oxide}

Graphene oxide (GO), obtained commercially from SigmaAldrich, was characterized according to Clemente et al. (2017). Only carbon and oxygen atoms were identified in the survey spectrum, suggesting an extremely pure sample. In addition, an oxygen content of approximately $32.2 \%$ was found, confirming the presence of oxygenated groups on the GO surface. The GO remained stable for 4 days ( $96 \mathrm{~h}$ ) in ultrapure water, presenting about $70 \%$ of the initial absorbance.

The slower aggregation of GO in the presence of HA can be explained by the fact that, due to the ionic strength of the medium, there was an increase in surface charge density and a reduction in repulsive electrostatic strength, which, as a result, caused aggregation of the material (He et al. 2017).

\section{Dispersion stability of graphene oxide in the presence and absence of humic acid}

In reconstituted water (zebrafish media), there was intense aggregate formation and rapid GO precipitation, reducing the initial absorbance to almost $0 \%$ after $24 \mathrm{~h}$ of incubation.

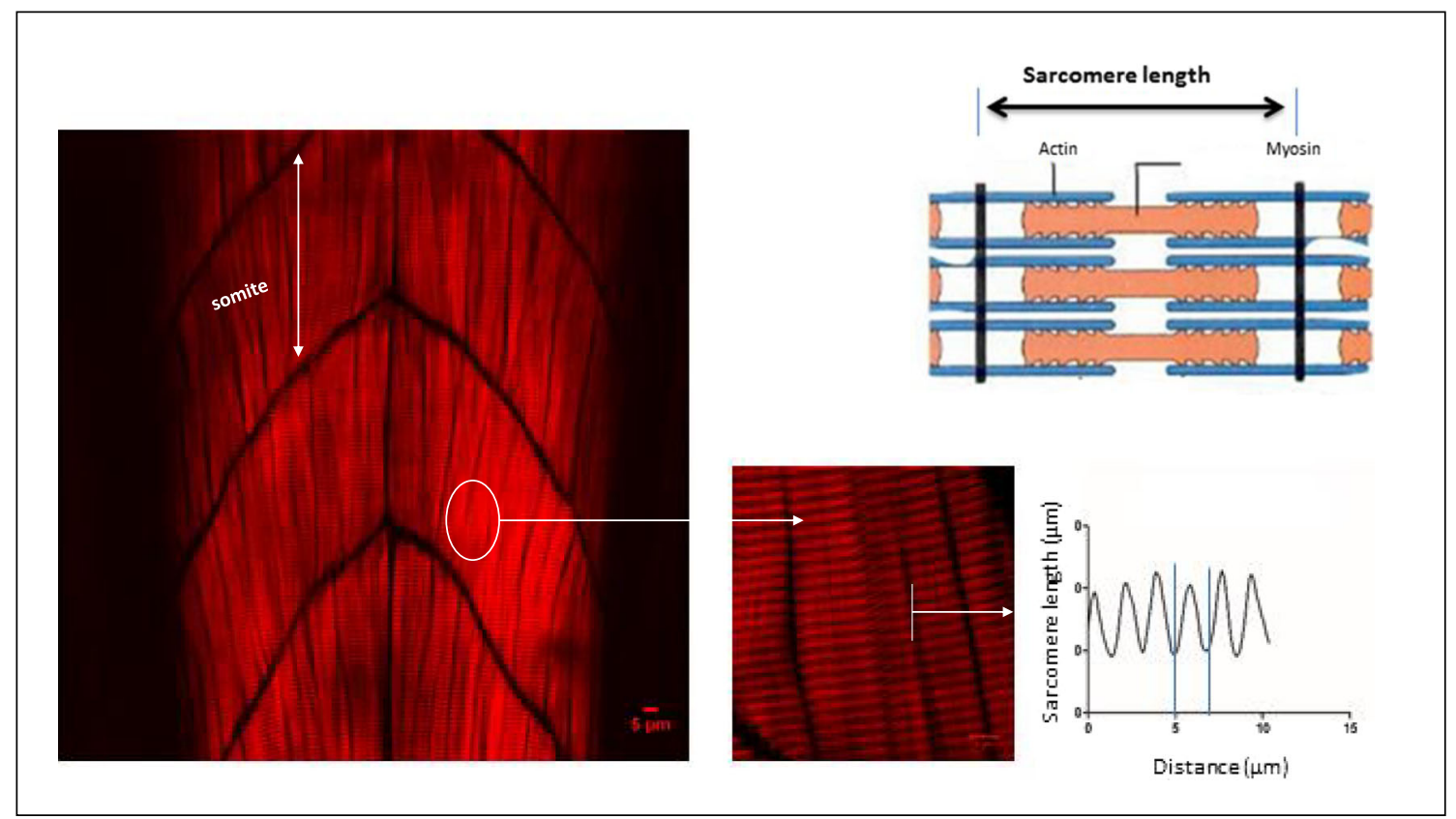

Fig. 1 Measurement of the length of the zebrafish larvae sarcomeres 
The dispersion-aggregation of graphene-based nanomaterials and their desorption properties may be modified depending upon their surrounding solution chemistry and environmental conditions, which control the transport and fate of graphene-based nanomaterials and pollutants (Huang et al. 2019). Recent studies have demonstrated that the presence of humic acid can enhance the stability of graphene oxide in aquatic environments. Furthermore, it has been reported that graphene oxide can adsorb humic acid via hydrogen bonds, Lewis acid-base interactions, $\pi-\pi$ interactions, and steric repulsions (Clemente et al. 2017; He et al. 2017). The presence of NOM enhanced the steric hindrance among the particles and subsequently increased particle stability during transport. The NOM increased the absolute surface potentials of carbon nanoparticles by absorbing at the particle surface. As a consequence, the electrostatic repulsion among particles increased resulted in less retention (Jahan et al. 2019). GO morphology, aggregation, and transport behavior would be significantly altered by NOM, especially NOM fractions that are highly aromatic and have a larger molecular weight (Shen et al. 2019)

The addition of HA to reconstituted water enhanced the GO stability, similar to ultrapure water, but aggregation was slow. The addition of HA in reconstituted water enhanced the GO stability, similar to ultrapure water, with slow aggregation. In fact, after 96 h, GO showed $90 \%$ of its initial absorbance (Clemente et al. 2017).

\section{Bioassays-mortality or malformation}

The production of GO is increasing and it can be released into different environmental compartments. In addition, the presence of HA in the medium increases its colloidal stability. Indeed, GO in the presence of HA had a pronounced effect on the development of zebrafish embryos (Clemente et al. 2017) and on some other organisms (Castro et al. 2018).

Throughout the present study, the mortality of the organisms was less than $10 \%$ for all groups, including the control group, validating the results obtained (OECD 2013). All the live embryos hatched between 3 and $4 \mathrm{dpf}$, and larvae exposed to GO for 5 days were smaller in relation to those of the control group and showed a reduction in yolk sac size (Fig. 2a, panel E). The presence of HA in the exposure medium reduced this effect of GO after 7 days of exposure (Figs. 2a, b, panel E). ANOVA data of zebrafish malformation and behavior are presented in supplementary material-Table S1.

D'Amora et al. (2017) verified that GO induced a significant reduction in the hatching rates, heart beat rate, and frequency of movement. At 50 and $100 \mu \mathrm{g} \mathrm{mL}{ }^{-1}$, the survival rates were under $80 \%$ between 72 and $120 \mathrm{hpf}$, respectively. In the present study, however, GO exposure were not able to interfere on the timing of hatch due to its coating. In this way, some authors observed that hatching rates were unaltered by GO (Soares et al. 2017) and apparently GO did not block the pores of the chorion of approximately $0.6 \mathrm{~mm}$ in diameter, allowing the nanomaterials to pass through the chorion by passive diffusion (D'Amora et al. 2017). Chen et al. (2016a), instead of GO coating, also observed that GO spontaneously penetrated the chorion, entered the embryo via endocytosis, damaged the mitochondria, and primarily translocated to the eye, heart, and yolk sac regions.

\section{Penetration of fluorescein-labeled graphene oxide in the embryos}

The adsorption of FTIC by GO and the confocal microscopy images of the embryos incubated with GO-FTIC, only detected the presence of GO-FTIC aggregates in embryos exposed to $1 \mathrm{mg} \mathrm{L}^{-1}$ (Fig. 3 panel d).

Fluorescein-labeled graphene oxide was used to visually confirm the penetration of GO through the embryo chorion and to relate this to the results of the bioassays. In the literature, the occurrence of malformations and histopathological lesions has been reported in the gut, liver, gills, and heart of zebrafish exposed to GO (Souza et al. 2017; Wang et al. 2015b). Despite the fact that the technique allowed the visualization of an increase in fluorescence around the chorion and the embryo with increasing exposure concentration to GOFTIC, autofluorescence similar to FTIC was observed in the control group embryos. Thus, it was not possible to be sure about the presence of GO in the embryo.

The optical properties of a NP can interfere with the endpoint measurement of absorbance or fluorescence in a biochemical assay. Higher concentrations of NPs (> $10 \mathrm{mg} / \mathrm{L})$ have a greater probability of interfering with assay function, and the use of such concentrations is not uncommon in toxicological studies. The addition of analytes (i.e., cells, tissue sample) will modify the degree of NP interference; therefore, the practice of testing for interference by measuring addition of NP to assay reagents may not be adequate. In case graphene shows interference, possible solutions may be to use wavelengths that will not overlap with that of graphene. Thus, due to the many potential artifacts when testing nanomaterials, it is always wise to use more than one type of assay based on different principles. Quality control practices will allow for the appropriate interpretation and evaluation of published results and provide accurate scientific data for the establishment of regulations related to safe NP production, utilization, and disposal (Ong et al. 2014; Park et al. 2017). Moreover, the use of fluorescence can lead to artifacts in uptake and translocation studies also with nanoplastic (Catarino et al. 2019; Schür et al. 2019).

Determination of the absorption of NM requires detection in internal tissues, which has been limited by available technology. For carbon-based NM, the methods most employed to determine embryo penetration by GO are radio-labeled 

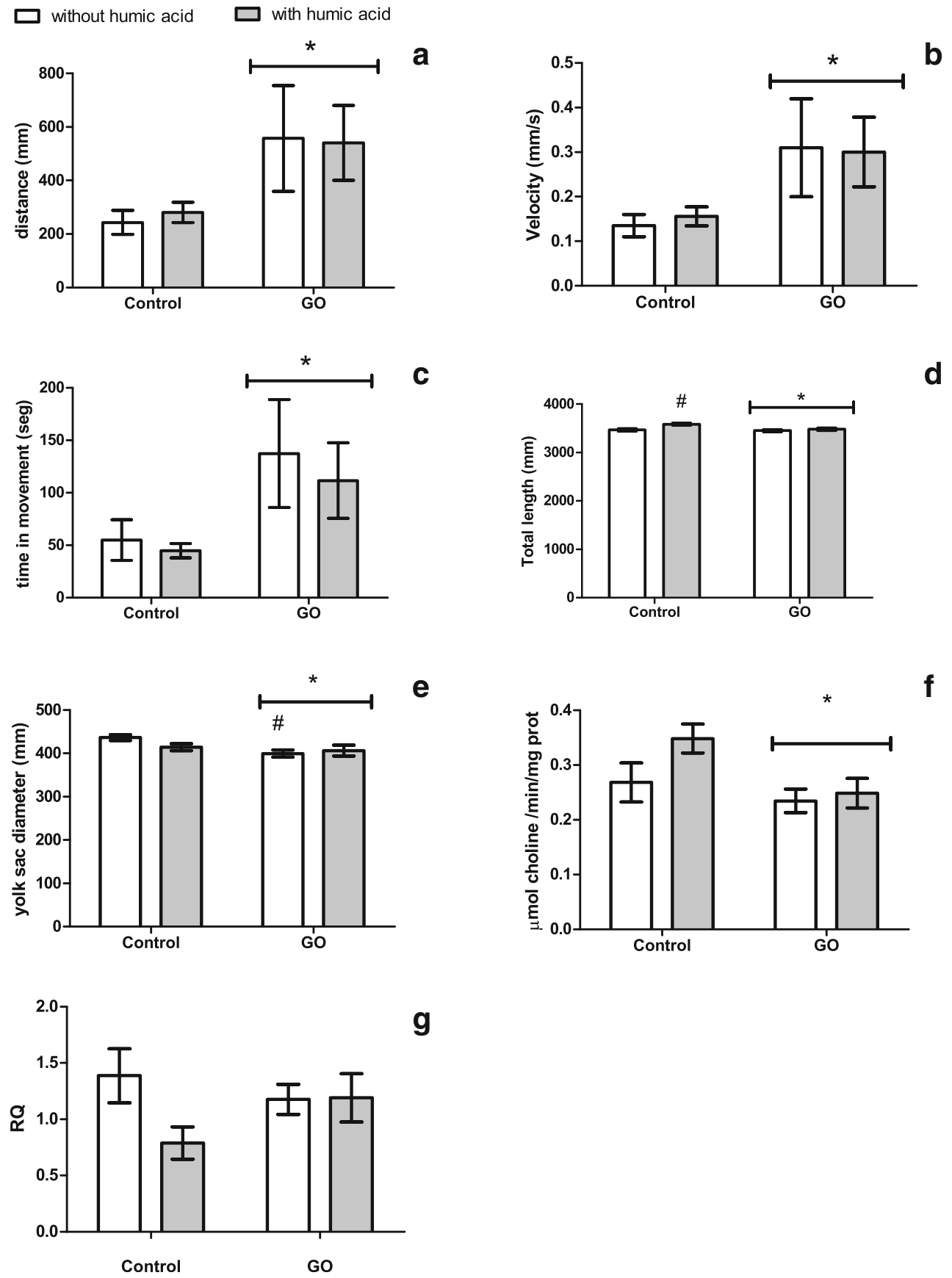

Fig. 2 Physical and behavioral analysis $(n=12)$ of five (a) and seven (b) day zebrafish larvae after GO exposure. The parameters measured were $\mathrm{A}$ - distance, B - velocity, C - time, D - total length, E - yolk sac, F - AChE

activity, and G - RQ. ${ }^{*} p<0.05$ in relation to the control groups; \# $p<$ 0.05 in relation to the control group without humic acid, $\bullet p<0.05$ in relation to the GO group without humic acid

materials or organic solvent extractions, although others could be developed (Handy et al. 2018). Su et al. (2017) found that small few-layer graphene particles exhibited greater bioaccumulation in zebrafish embryos and stronger chorion penetration ability than larger ones. The uptake measurements were done by high-resolution transmission electron microscope (HRTEM) analysis and radioactivity, using liquid scintillation counting. In vitro tests could also be carried out to investigate GO uptake by cells using a flow cytometer (Oh et al. 2017).

Since particle size is an important physicochemical factor accounting for the uptake, internalization, and subsequent distribution of NMs (van Pomeren et al. 2017) and in systems that are not colloidally stable, the NM may aggregate in the cell media and form aggregates that are too large for cell internalization and remain fixed to the outer cell membrane (Paatero et al. 2017); it may also be that the developmental phase of the zebrafish did not favor the uptake of NM. The function of the biological barriers for transport and 

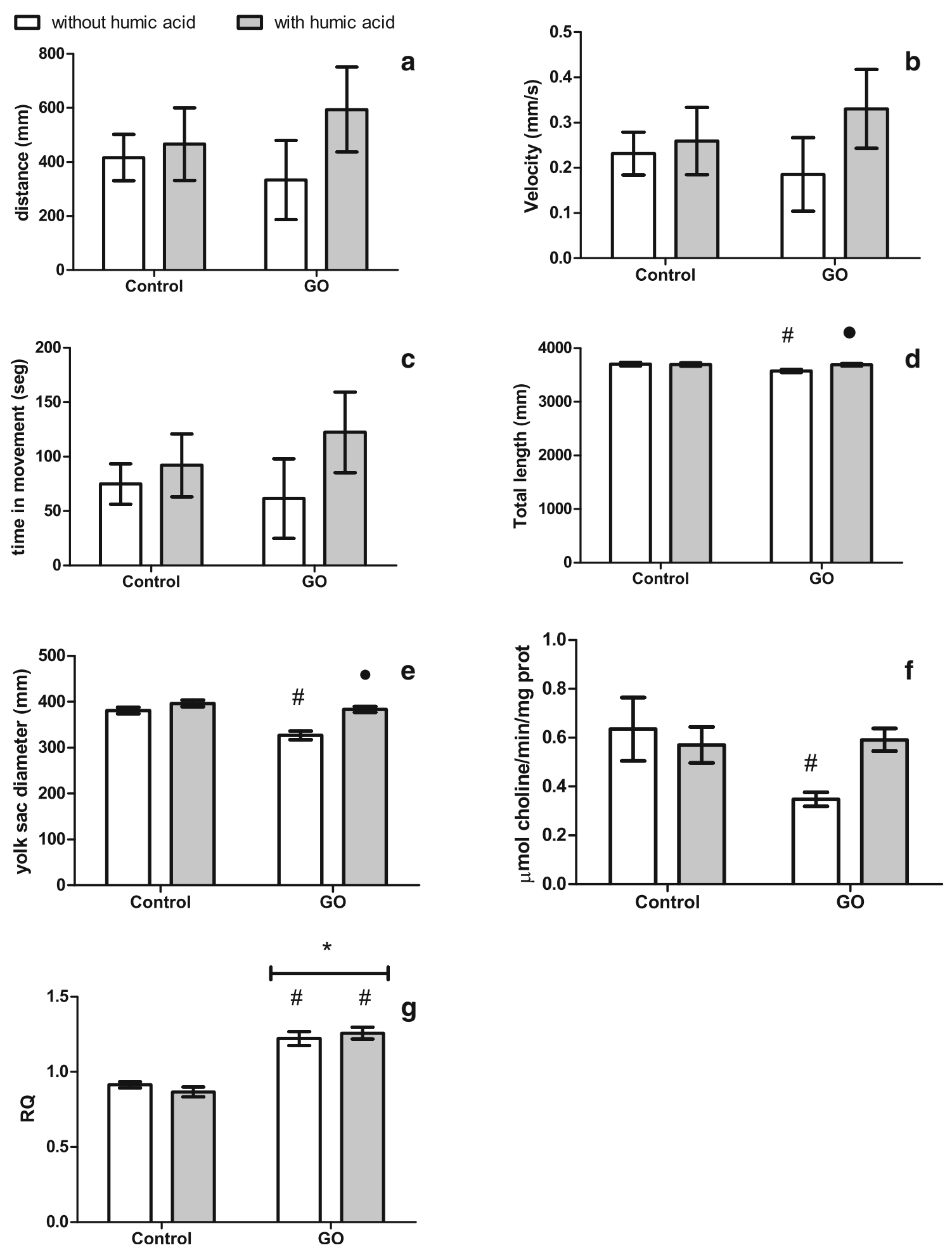

Fig. 2 (continued)

biodistribution gradually matured from 3 to $7 \mathrm{dpf}$, and together with their maturation, the transport and biodistribution of NM could change ( $\mathrm{Li}$ et al. 2017). Thus, to improve the accuracy of embryo nanotoxicity evaluation in future studies, tests will be carried out on different dpf to identify critical windows for exposure and with other methods beyond fluorescence detection to verify GO tissue penetration since artifacts can lead to erroneous conclusions.

Although the penetration of the GO used in this study into the embryos was not completely confirmed, the effects due to 


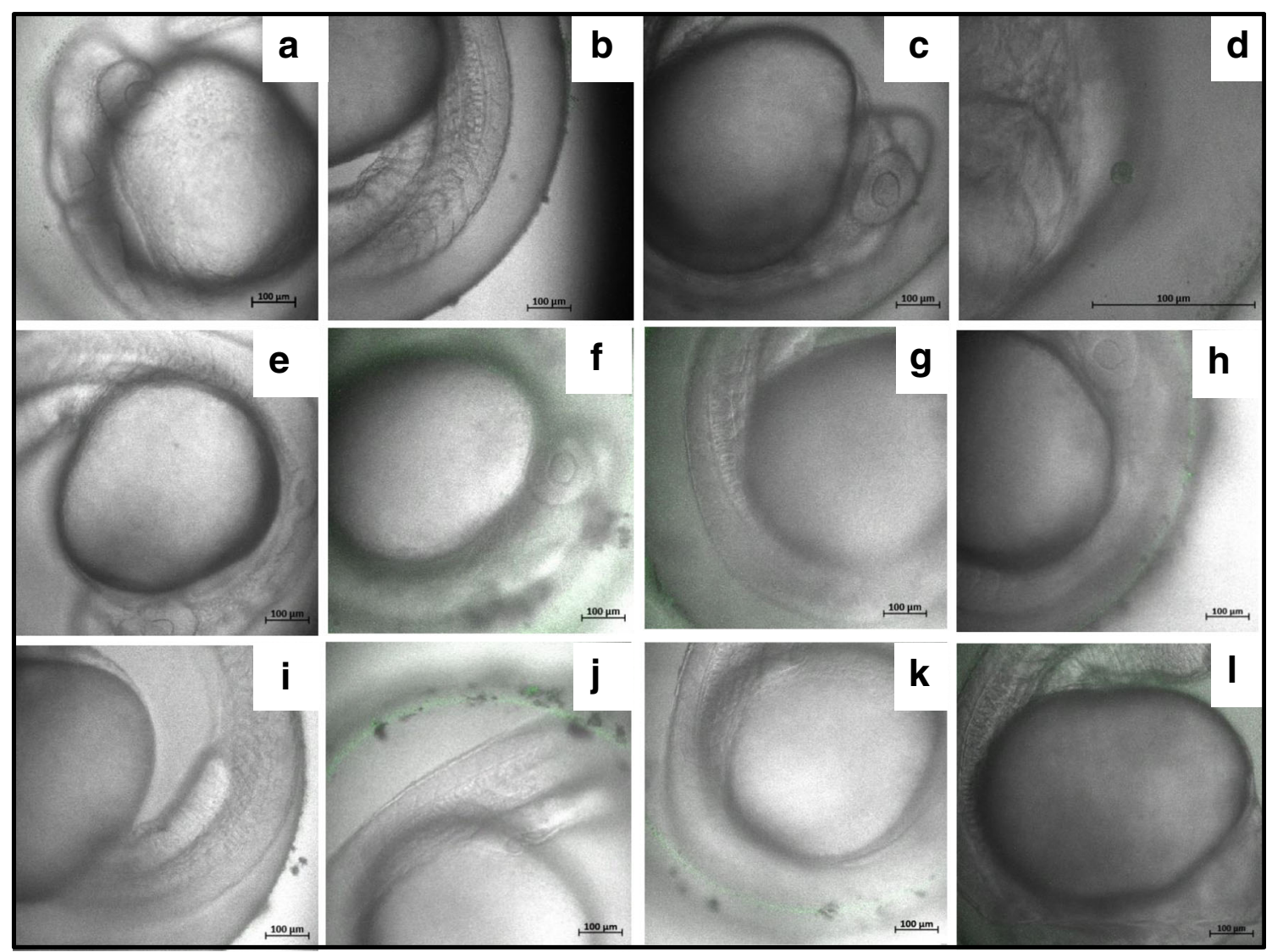

Fig. 3 Demonstrative images of the confocal microscopy of zebrafish embryos after 2-h incubation with GO-FTIC. a, b Control; c, d 1 mg/L GO; e 10 mg/L GO; f, g 100 mg/L GO; h, i 1 mg/L GO + HA; j, $\mathbf{k} 10$ mg/L GO + HA; 1100 mg/L GO + HA. The black arrow indicates a GO aggregate

exposure to this NM were observed. It can be discussed if the GO penetrated or not the embryo by chorion. Some papers in the literature indicate the occurrence of graphene internalization in zebrafish embryos (Chen et al. 2015; Wang et al. 2015b). These excellent papers about GO toxic effects usually promoted a static renewal of media every day and then ensured the maintenance of GO concentration (Dasmahapatra et al. 2019). Although these results have substantially increased our understanding of the basic mechanisms underlying the effects of GO toxicity, this knowledge was obtained from studies based on high-GO levels and may overestimate GO toxicity. About this, the stability of nanomaterials in a real aquatic environment governs their ecotoxicity and may interfere with its availability to the organisms. For example, NP may be coated with biomolecules almost spontaneously (Falahati et al. 2019). Also, HA has a shielding effect on GO adsorption rate of molecules ( $\mathrm{Lu}$ et al. 2018). These interferences ultimately decrease the available concentration of GO to organisms.

The permeability and structure of the chorion change throughout embryonic development and can be altered by exposure to xenobiotics. For approximately $72 \mathrm{~h}$, the developing embryo is enveloped by the chorion, which, according to Pelka et al. (2017), acts as a barrier to molecules larger than 4000 Da.

However, they noticed that other parameters such as lipophilicity, charge, and specific molecular conformation may play an important role in the definition of the uptake of chemicals across the chorion of the zebrafish embryo. Additionally, a progressive change in the chorion structure has been reported during embryonic development. In consequence, future studies are needed to understand chorionic influences on the uptake of chemicals ranging in molecular size and physicochemical properties among fish models (Kristofco et al. 2018).

The chorion is a 1.5 - to $2.5-\mu \mathrm{m}$-thick acellular membrane composed of 3 layers, perforated by porous channels that are uniformly distributed throughout it and range from $0.2 \mu \mathrm{m}$ (in the unfertilized egg) to $0.5-0.7 \mu \mathrm{m}$ in fertilized eggs. Thus, considering that the literature has reported chorion pore sizes between $300 \mathrm{~nm}$ and $1.0 \mu \mathrm{m}$ (Lin et al. 2013), it is possible that GO could penetrate the chorion and reach the embryo, due to its hydrodynamic size (particle diameter in suspension) of approximately $255 \mathrm{~nm}$ at least during initial $24 \mathrm{~h}$.

Beyond, the ultralow concentration of GO was able to cross the cell membrane and accumulated on larvae organs (Ren 
et al. 2016). Indeed, Zhang et al. (2017) noticed that there was a nonmonotonic response of zebrafish developmental toxicity to $\mathrm{GO}$ at microgram per liter to milligram per liter levels. According to them, the development of zebrafish embryos exposed to trace concentrations (1-100 $\mu \mathrm{g} / \mathrm{L})$ of GO was impaired because of DNA modification, protein carbonylation, and excessive generation of reactive oxygen species. Thus, even with the GO's aggregation, a small amount of GO that were able to penetrate the embryo may have caused the observed changes. This hypothesis should be better evaluated in future studies on embryos with and without chorion. In future analyses, exposures can be performed on embryos that have been removed from the chorion which increases the GO's ability to enter the embryo in order to compare the effects with current data.

Moreover, HA altered the uptake and deposition of GO and decreased the aggregation of GO in embryonic yolk cells and deep layer cells (Chen et al. 2015). Some studies revealed that solution chemistry could affect the heteroaggregation behavior of GO (Feng et al. 2019). The existence of branches in HA molecules may result in the formation of looser coils or network formation may have an effect on the extent of agglomeration with ionic strength (Batley et al. 2013). Thus, interactions between nanomaterials and HA may be influenced by the concentration of HA (Huang et al. 2019).

Nevertheless, dynamic of GO aggregation in test media should be better studied. Because aggregation or agglomeration of GO can change its size, effective surface area, and other physicochemical properties, it may modulate its toxicity to aquatic organisms and could interfere with GO's ability to pass through the chorion (Dasmahapatra et al. 2019).

\section{Behavioral analysis}

Zebrafish are also considered to be an excellent animal model for the investigation of developmental toxicity mechanisms in environmental studies. The zebrafish brain shows complex cognition and biochemical functionality, comparable to that of mammals (Meshalkina et al. 2017; Strungaru et al. 2018).

Some evidence of GO neurotoxicity has recently been published in the literature. Mendonça et al. (2015) reported that reduced GO induces a transient opening in the blood-brain barrier, being found mainly in the thalamus and hippocampus of rats. The motor development of zebrafish embryos provides a framework for neurotoxicity studies.

During embryogenesis, zebrafish embryos exhibit spontaneous movements, referred to as coiling. The locomotor repertoire of the zebrafish larva is relatively stereotyped (Airhart et al. 2007; Drapeau et al. 2002), with some possible maneuver categories (Knafo and Wyart 2018). Swimming starts when the pre-motor chemical synaptic unit integrates since this movement requires functional neuromuscular coordination. The swim bladder and sensory systems such as vision become functional $5 \mathrm{dpf}$, and the larvae then begin to move and swim spontaneously (Colwill and Creton 2011; Drapeau et al. 2002). Swimming becomes sustained when serotonergic modulation is integrated (Colwill and Creton 2011).

The results obtained indicated that, regardless of the presence of HA, the larvae exposed to GO for 5 days showed an increase in locomotor activity. Larvae exposed to GO for 5 days swam longer distances at greater velocities than the control groups and showed movement for longer periods (Fig. 2a, panels B and C). However, the tests carried out in larvae after 7 days of exposure showed no statistically significant differences between the groups with respect to locomotor activity (Fig. 2b, panels A-D).

The greater physical activity of the 5-day larvae may have resulted in greater energy expenditure by this group, as evidenced by the reduction in yolk sac size. Larvae exposed to GO for 5 days were also smaller than those of the control group. The yolk sac plays an important role during the early developmental stage since it is the only source of nutrition for zebrafish embryos. The loss of nutrients may induce growth inhibition in zebrafish embryos (Qiang et al. 2016).

In order to verify the persistence of the effects observed, the tests were repeated after 7 days of exposure but did not show statistically significant differences between groups with respect to locomotor activity. The results lead one to suppose that on $7 \mathrm{dpf}$, compensatory mechanisms minimize the behavioral changes previously observed.

Neural networks in the spinal cord are responsible for the generation and execution of movements in zebrafish. The activity of the spinal neuronal circuits is regulated principally by the cholinergic system, that differentially controls the excitability of distinct classes of motoneurons in a muscarinicdependent manner, that seems to serve as a plasticity mechanism to alter the operational range of the locomotor networks (Bertuzzi and Ampatzis 2018). Cholinergic signaling has critical roles during central nervous system development and functional neuronal $\mathrm{nAChRs}$ are present within the spinal cord at the time when locomotor output in zebrafish first begins to manifest itself (Menelaou et al. 2014). In the developing spinal cord, the motoneurons play an active role in the regulation of motor activity. However, at the beginning of zebrafish development, the motoneurons release a second excitatory transmitter (glutamate) in addition to Ach at the neuromuscular junction, and this phenomenon is abolished or reduced later in development (Falgairolle and O’Donovan 2019).

\section{Analysis of acetylcholinesterase activity}

AChE activity can be used as a marker of cholinergic function since it regulates the amount of $\mathrm{ACh}$ that interacts with its receptors, and zebrafish embryos represent a suitable model to study acetylcholinesterase inhibition (Kais et al. 2015; Koenig et al. 2016). The AChE activity is expressed as from 
14 hpf in zebrafish (Valim Brigante et al. 2018) and its inhibition can lead to spine curvature and shortened tails in the embryos (Jeon et al. 2016). Previous studies showed that the exposure of zebrafish of $96 \mathrm{hpf}$ to an AChE activity inhibitor (chlorpyrifos) may lead to a decreased locomotion (Jin et al. 2015).

The timing and duration of developmental exposure to cholinesterase inhibitors can influence the nature of behavioral response profiles.

In the present study, an alteration in AChE activity was observed in the group exposed to GO after 5 and 7 days of exposure as compared with the control group. On the other hand, the enzyme activity was the same in the group coexposed to HA (Figs. 2a, b, panel F).

$\mathrm{Hu}$ et al. (2017) showed that exposure of the parents to trace concentrations of $\mathrm{GO}\left(0.01\right.$ to $\left.1 \mu \mathrm{g} \mathrm{L}^{-1}\right)$ did not provoke obvious neurotoxicity in the parents, but did in their offspring, which presented a reduction in AChE activity among other effects. In fact, it seems there is significant inhibition of $\mathrm{AChE}$ by carbon nanomaterials (CNT), probably due to their high affinity for AChE (Wang et al. 2009) in different organisms such as bivalves (De Marchi et al. 2018b) and in fish (Cimbaluk et al. 2018). AChE responds to various stresses including oxidative stress (Chacon et al. 2003), and the literature reports a role of HA as a metal and ROS sequestrant (Kudryasheva and Tarasova 2015; Ozkan et al. 2015). Chen et al. (2016b) indicated that the exposure of zebrafish embryos to GO caused changes in oxidative stress biomarkers on the first and fourth days of exposure, but that the values were normalized after 8 and 14 days of exposure (1 to $10 \mathrm{mg} \mathrm{L}^{-1}$ GO). Thus, HA could prevent some of the oxidative stress effects on AChE.

It is also possible that GO leads to an interruption in homeostasis during the developmental plasticity phase of zebrafish. In addition to the cholinergic systems, other systems such as the dopaminergic system play a role in the development of locomotion and swimming (Lia et al. 2017; Pereira et al. 2012; Reimer et al. 2013; Smeets and Gonzalez 2000). Indeed, exposure to GO caused behavioral changes in zebrafish larvae due to a loss of dopaminergic neurons $(\mathrm{Hu}$ et al. 2017; Ren et al. 2016; Soares et al. 2017), which could be verified in future studies.

\section{Extraction of RNA and qPCR}

An increase in the expression of AChE may have been one of the mechanisms involved in AChE homeostasis. Kaufer et al. (1998) showed that a modulated cholinergic gene expression acted to reduce available acetylcholine and depress cholinergic neurotransmission following stress such as forced swimming or after exposure to AChE inhibitors. The authors proposed a bidirectional modulation of genes that regulate acetylcholine availability after stress and a blockade of AChE that involves calcium-dependent changes in the gene expression.

In the present study, the RT-PCR analysis indicates a lack of statistically significant difference among the groups with respect to the $\mathrm{AChE}$ gene expression on $5 \mathrm{dpf}$ fishes but not on 7 dpf ones when the RT-PCR gene expression analysis evidenced an increase in the AChE expression (Figs. 2a, b, panel G).

Toxicants may modulate the acetylcholinesterase activities not only by direct interaction with the enzyme but also by manipulating the expression and biosynthesis of acetylcholinesterase or by neuronal cell degeneration (Kais et al. 2015). Altenhofen et al. (2017) suggested that the inhibition of AChE may induce increased availability of ACh in the synaptic cleft, possibly due to posttranscriptional or post-translational modulation. It has further been suggested that changes in the AChE mRNA expression may be due to changes in transcription factors, which consequently alter cell signaling and gene expression (Akinyemi et al. 2017). In this way, GO could inhibit RNA translation into protein. This hypothesis is supported by fish results on day 7 which behavior recovery may be due to an increase in mRNA expression, but with a decrease in AChE activity.

\section{Morphological muscle analyses}

Behavioral changes in zebrafish larvae may be related to a breakdown of myosin fibers, resulting in changes in the skeletal muscle (Peng et al. 2015), or to a microstructural disorder with shortening of the sarcomeres (Huang et al. 2011). The muscle tissue images obtained by SHG in this study did not indicate morphological differences between the groups and there were no statistically significant differences between the groups in relation to the somites and sarcomeres (Fig. 4). Thus, changes observed in larval size and $\mathrm{AChE}$ activity do not appear to be related to changes in the muscle tissue. The occurrence of some disturbance during neurological development may result in the disruption of normal development. The larvae at 5 and 7 dpf were showed in Fig. 5.

Locomotion is usually controlled by neuronal networks (Le Ray et al. 2011). The relationship between behavior and the neural system has been studied in zebrafish. For example, the mycotoxin ustiloxin A can cause developmental impairment and growth inhibition on early life zebrafish including shorter body length probably due to a microtubule inhibition and gene expression damage (Hu et al. 2019). Moreover, significantly abnormalities of $n t l$ and $s h h$ expression were consistent with body length reduction in deltamethrin-treated groups (Liu et al. 2018). 

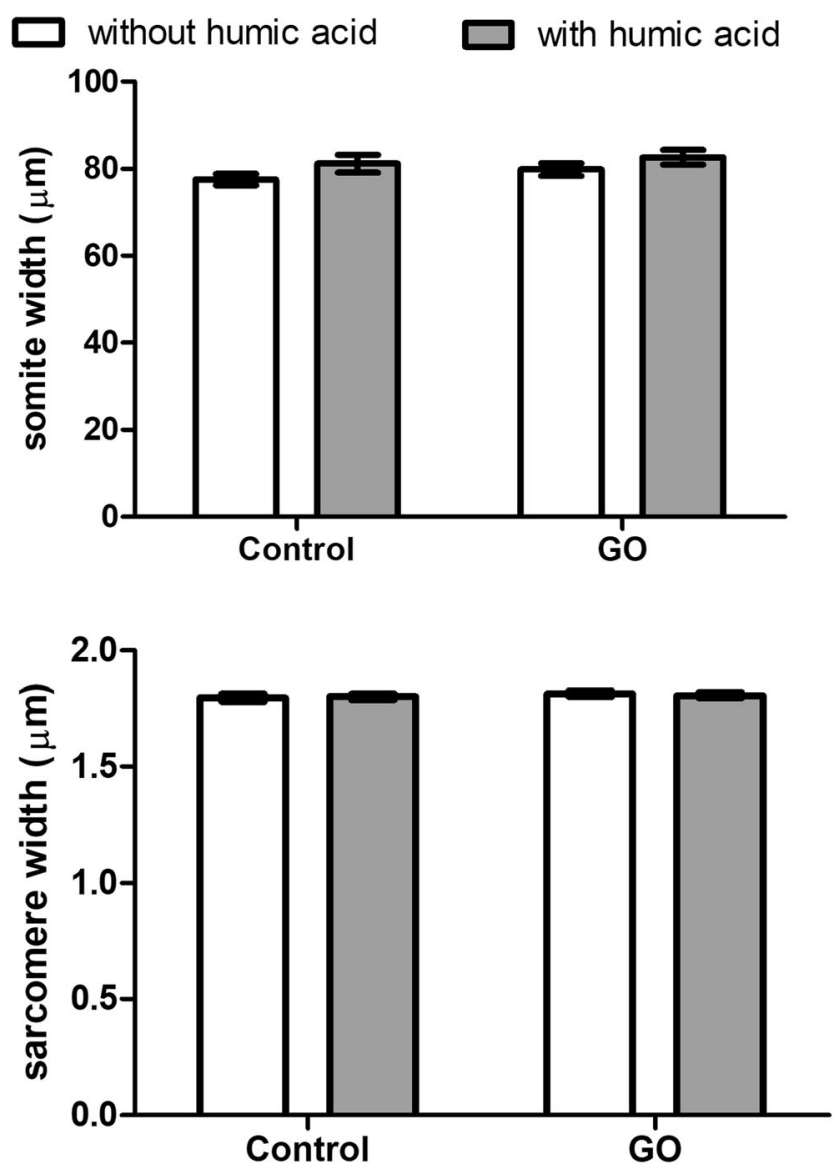

Fig. 4 Analysis of the muscle tissue of 5-day zebrafish larvae. The parameters measured were the widths of the somites and sarcomeres $(\mu \mathrm{m})$ after exposure to $100 \mathrm{mg} / \mathrm{L}$ GO in the presence or not of HA. In each group, 20 measurements of somites 20-24 of 5 larvae were made. For the analysis of the sarcomeres, 5 larvae/group were used and 20 measurements made of each one

An alteration in $\mathrm{ACh}$ levels at the neuromuscular junction could impact muscle development. Thus, it is possible that other factors may be involved in the obtained results. In fact, some molecular interactions and unexplored mechanisms may contribute to the GO developmental toxicity. During innervation, the structural specializations of the postsynaptic membrane are maintained by a specialized network of the cortical actin cytoskeleton and comprising, in addition to muscle-specific receptor tyrosine kinase (MuSK) and rapsyn, the dystrophin-glycoprotein complex. Activation of MuSK triggers the assembly of a postsynaptic cytoskeletal scaffold that clusters Ach receptors through the associated cytosolic protein rapsyn (Tintignac et al. 2015). Also, GO aggregation might favored this unchanged muscle tissue images since the amount that can cross the chorion during this critical period might be decreased.

\section{Conclusion}

The present study demonstrated that exposure to GO was capable of inducing biochemical, morphological, and behavioral changes in zebrafish larvae even with the aggregation of part of the GO concentration. These effects were evident after 5 days of exposure. After 7 days of exposure, the reductions in the larval and yolk sac sizes and in acetylcholinesterase activity persisted, but the behavioral changes were no longer evident, indicating that compensation mechanisms established homeostasis in the zebrafish development. Increased expression of AChE appears to be one of the compensatory mechanisms involved in the effects observed here and HA seems to be associated with the modulation of the risk of GO toxicity. The recovery of the parameters evaluated could also be related to a reduction in the reactive species generated due to exposure to GO by the HA. These hypotheses should be better evaluated in future studies.
Fig. 5 Zebrafish embryos and larvae exposed to $\mathrm{GO}(100 \mathrm{mg}$ $\left.\mathrm{L}^{-1}\right)$ and/or HA $\left(20 \mathrm{mg} \mathrm{L}^{-1}\right)$ at 5 $\mathrm{dpf}$ (a control, c GO, e GO + HA $\mathrm{g} \mathrm{HA}$ ) and $7 \mathrm{dpf}$ (b control, d GO, f GO + HA, h HA)

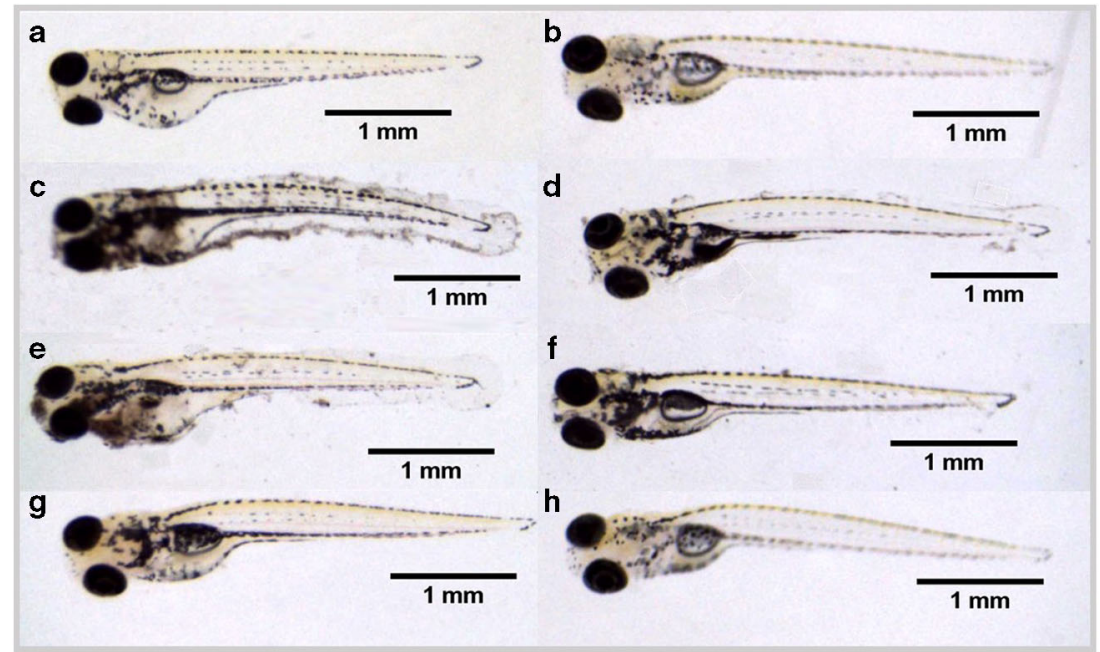


Acknowledgments The authors are grateful to the CNPEM openfacilities (LCS, LAM, LMN, NBT, and LMG), CAPES, the Brazilian National Institute for Science, Technology and Innovation on Complex Functional Materials (INCT-Inomat), the Brazilian Nanotoxicology Network (Cigenanotox), the Brazilian Network of Nanotechnology Applied to Agro-business (AgroNano), and the National System of Laboratories on Nanotechnologies (SisNANO).

Funding information This work was supported by grants (2014/12891-0, 2014/01995-9, and 2014/15640-8) received from the São Paulo Research Foundation (FAPESP). INFABIC was co-funded by FAPESP (08/579063 ) and the National Council for Scientific and Technological Development (CNPq) (573913/2008-0).

\section{Compliance with ethical standards}

Conflict of interest The authors declare that they have no conflict of interests.

\section{References}

Airhart MJ, Lee DH, Wilson TD, Miller BE, Miller MN, Skalko RG (2007) Movement disorders and neurochemical changes in zebrafish larvae after bath exposure to fluoxetine (PROZAC). Neurotoxicol Teratol 29(6):652-664

Akinyemi AJ, Oboh G, Fadaka AO, Olatunji BP, Akomolafe S (2017) Curcumin administration suppress acetylcholinesterase gene expression in cadmium treated rats. Neurotoxicol 62:75-79

Altenhofen S, Wiprich MT, Pereira TCB, Bogo MR, Bonan CD (2017) Tebuconazole alters morphological, behavioral and neurochemical parameters in larvae and adult zebrafish (Danio rerio). Chemosphere 180:483-490

Batley GE, Kirby JK, McLaughlin MJ (2013) Fate and risks of nanomaterials in aquatic and terrestrial environments. Acc Chem Res 46:854-862

Behra M, Cousin X, Bertrand C, Vonesch J-L, Biellmann D, Chatonnet A, Strähle U (2002) Acetylcholinesterase is required for neuronal and muscular development in the zebrafish embryo. Nat Neurosci 5(2):111-118

Bertuzzi M, Ampatzis K (2018) Spinal cholinergic interneurons differentially control motoneuron excitability and alter the locomotor network operational range. Sci Rep 8:1988

Botero WG, de Oliveira LC, Cunha BB, de Oliveira LK, Gouveia D, Rocha JC, Fraceto LF, Rosa AH (2011) Characterization of the interactions between endocrine disruptors and aquatic humic substances from tropical rivers. J Braz Chem Soc 22(6):1103-1110

Bradford M (1976) A rapid and sensitive method for the quantification of microgram quantities of protein utilizing the principle of protein-dye binding. Anal Biochem 72:248-254

Bramini M, Sacchetti S, Armirotti A, Rocchi A, Vasquez E, Castellanos V, Bandiera T, Cesca F, Benfati F (2016) Graphene oxide nanosheets disrupt lipid composition, $\mathrm{Ca}^{2+}$ homeostasis, and synaptic transmission in primary cortical neurons. ACS Nano 10(7):7154-7171

Bundschuh M, Filser J, Lüderwald S, McKee M, Metreveli G, Schaumann G, Schulz R, Wagner S (2018) Nanoparticles in the environment, where do we come from, where do we go to? Environ Sci Eur 30(1):6

Castro VL, Clemente Z, Jonsson C, Silva M, Vallim JH, Medeiros AMZ, Martinez DST (2018) Nanoecotoxicity assessment of graphene oxide and its relationship with humic acid. Environ Toxicol Chem 37: 1998-2012. https://doi.org/10.1002/etc.4145

Catarino AI, Frutos A, Henry TB (2019) Use of fluorescent-labelled nanoplastics (NPs) to demonstrate NP absorption is inconclusive without adequate controls. Sci Total Environ 670:915-920. https:// doi.org/10.1016/j.scitotenv.2019.03.194

Chacon MA, Reyes AE, Inestrosa NC (2003) Acetylcholinesterase induces neuronal cell loss, astrocyte hypertrophy and behavioral deficits in mammalian hippocampus. J Neurochem 87:195-204

Chen Y, Hu X, Sun J, Zhou Q (2016a) Specific nanotoxicity of graphene oxide during zebrafish embryogenesis. Nanotoxicology 10:42-52

Chen M, Yin J, Liang Y, Yuan S, Wang F, Song M, Wang H (2016b) Oxidative stress and immunotoxicity induced by graphene oxide in zebrafish. Aquat Toxicol 174:54-60. https://doi.org/10.1016/j. aquatox.2016.02.015

Cheng J, Flahaut E, Cheng SH (2007) Effect of carbon nanotubes on developing zebrafish (Danio rerio) embryos. Environ Toxicol Chem 26(4):708-716

Cheng Y, Ren C, Ouyang S, Hu X, Zhou Q (2015) Mitigation in multiple effects of graphene oxide toxicity in zebrafish embryogenesis driven by humic acid. Environ Sci Technol 49(16):10147-10154

Chowdhury I, Mansukhani ND, Guiney LM, Hersam MC, Bouchard D (2015) Aggregation and stability of reduced graphene oxide, complex roles of divalent cations, $\mathrm{pH}$, and natural organic matter. Environ Sci Technol 49(18):10886-10893

Cimbaluk GV, Ramsdorf WA, Perussolo MC, Santos HKF, da Silva de Assis HC, Schnitzler MC, Schnitzler DC, Carneiro PG, Cestari MM (2018) Evaluation of multiwalled carbon nanotubes toxicity in two fish species. Ecotoxicol Environ Saf 150:215-223

Clemente Z, Castro VL, Franqui L, Silva C, Martinez DST (2017) Nanotoxicity of graphene oxide, assessing the influence of oxidation debris in the presence of humic acid. Environ Pollut 225:118-128

Colwill RM, Creton R (2011) Locomotor behaviors in zebrafish (Danio rerio) larvae. Behav Process 86(2):222-229

D'Amora M, Camisasca A, Lettieri S, Giordani S (2017) Toxicity assessment of carbon nanomaterials in zebrafish during development. Nanomaterials 7(12):E414. https://doi.org/10.3390/nano7120414

Dasari TP, Hwang HM (2013) Effect of humic acids and sunlight on the cytotoxicity of engineered zinc oxide and titanium dioxide nanoparticles to a river bacterial assemblage. J Environ Sci 25(9):1925-1935

Dasmahapatra AK, Dasari TPS, Tchounwou PB (2019) Graphene-based nanomaterials toxicity in fish. Rev Environ Contam Toxicol 247:158

De Marchi L, Neto V, Pretti C, Figueira E, Chiellini F, Morelli A, Soares AMVM, Freitas R (2018a) Toxic effects of multi-walled carbon nanotubes on bivalves, comparison between functionalized and nonfunctionalized nanoparticles. Sci Total Environ 622-623:15321542

De Marchi L, Pretti C, Gabriel B, Marques PAAP, Freitas R, Neto V (2018b) An overview of graphene materials: properties, applications and toxicity on aquatic environments. Sci Total Environ 631-632: $1440-1456$

Deng CH, Gong JL, Zeng GM, Jiang Y, Zhang C, Liu H-Y, Huan S-Y (2016) Graphene-CdS nanocomposite inactivation performance toward Escherichia coli in the presence of humic acid under visible light irradiation. Chem Eng J 284:41-53

Drapeau P, Saint-Amant L, Buss RR, Chong M, McDearmid JR, Brustein E (2002) Development of the locomotor network in zebrafish. Prog Neurobiol 68(2):85-111

Drews U (1975) Cholinesterase in embryonic development. Prog Histochem Cytochem 7:1-52

Ellman GL, Courtney KD, Andres V, Featherstone RM (1961) A new and rapid colorimetric determination of acetylcholinesterase activity. Biochem Pharmacol 7:88-95

Falahati M, Attar F, Sharifi M, Haertlé T, Berret JF, Khan RH, Saboury AA (2019) A health concern regarding the protein corona, aggregation and disaggregation. Biochim Biophys Acta Gen Subj 1863(5): 971-991 
Falgairolle M, O'Donovan MJ (2019) Feedback regulation of locomotion by motoneurons in the vertebrate spinal cord. Curr Opin Physiology 8:50-55

Feng Y, Huynh KA, Xie Z, Liu G, Gao S (2019) Heteroaggregation and sedimentation of graphene oxide with hematite colloids: influence of water constituents and impact on tetracycline adsorption. Sci Total Environ 647:708-715

Freixa A, Acuña V, Sanchís J, Farré M, Barceló D, Sabater S (2018) Ecotoxicological effects of carbon based nanomaterials in aquatic organisms. Sci Total Environ 619-620:328-337

Handy RD, Ahtiainen J, Navas JM, Goss G, Bleekere EAJ, von der Kammer F (2018) Proposal for a tiered dietary bioaccumulation testing strategy for engineered nanomaterials using fish. Environ Sci: Nano 5:2030-2046. https://doi.org/10.1039/C7EN01139C

He K, Chen G, Zeng G, Peng M, Huang Z, Shi J, Huang T (2017) Stability, transport and ecosystem effects of graphene in water and soil environments. Nanoscale 9(17):5370-5538

Hu X, Chen Q, Jiang L, Yu Z, Jiang D, Yin D (2011) Combined effects of titanium dioxide and humic acid on the bioaccumulation of cadmium in Zebrafish. Environ Pollut 159(5):1151-1158

Hu X, Wei Z, Mu L (2017) Graphene oxide nanosheets at trace concentrations elicit neurotoxicity in the offspring zebrafish. Carbon 117: 182-191

Hu Z, Dang Y, Liu C, Zhou L, Liu H (2019) Acute exposure to ustiloxin A affects growth and development of early life zebrafish, Danio rerio. Chemosphere 226:851-857

Huang SH, Hsiao CD, Lin DS, Chow CY, Chang CJ, Liau I (2011) Imaging of zebrafish in vivo with second harmonic generation reveals shortened sarcomeres associated with miopathy induced by statin. PLoS One 6(9):e24764

Huang D, Xu B, Wu J, Brookes PC, Xu J (2019) Adsorption and desorption of phenanthrene by magnetic graphene nanomaterials from water: roles of $\mathrm{pH}$, heavy metal ions and natural organic matter. Chem Eng J 368:390-399

Ivask A, Juganson K, Bondarenko O, Mortimer M, Aruoja V, Kasemets K, Blinova I, Heinlaan M, Slaveykova V, Kahru A (2014) Mechanisms of toxic action of $\mathrm{Ag}, \mathrm{ZnO}$ and $\mathrm{CuO}$ nanoparticles to selected ecotoxicological test organisms and mammalian cells in vitro, A comparative review. Nanotoxicology 8(Suppl 1):57-71. https://doi.org/10.3109/17435390.2013.855831

Jahan S, Alias YB, Bakar AFBA, Yusoff IB (2019) Transport and retention behavior of carbonaceous colloids in natural aqueous medium: impact of water chemistry. Chemosphere 217:213-222

Jeon H-J, Lee Y-H, Kim M-J, Choi S-D, Park B-J, Lee S-E (2016) Integrated biomarkers induced by chlorpyrifos in two different lifestages of zebrafish (Danio rerio) for environmental risk assessment. Environ Toxicol Pharmacol 43:166-174

Jin Y, Liu Z, Peng T, Fu Z (2015) The toxicity of chlorpyrifos on the early life stage of zebrafish: a survey on the endpoints at development, locomotor behavior, oxidative stress and immunotoxicity. Fish Shellfish Immunol 43:405-414

Kais B, Stengel D, Batel A, Braunbeck T (2015) Acetylcholinesterase in zebrafish embryos as a tool to identify neurotoxic effects in sediments. Environ Sci Pollut Res 22:16329-16339

Kaufer D, Friedman A, Seidman S (1998) Acute stress facilitates longlasting changes in cholinergic gene expression. Nature 393:373-377

Kim JY, Kim KT, Lee BG, Lim BJ, Kim SD (2013) Developmental toxicity of japanese medaka embryos by silver nanoparticles and released ions in the presence of humic acid. Ecotoxicol Environ Saf 92:57-63

Knafo S, Wyart C (2018) Active mechanosensory feedback during locomotion in the zebrafish spinal cord. Curr Opin Neurobiol 52:48-53

Koenig JA, Dao TL, Kan RK, Shih T-M (2016) Zebrafish as a model for acetylcholinesterase-inhibiting organophosphorus agent exposure and oxime reactivation. Ann N Y Acad Sci 1374:68-77
Kristofco LA, Haddad SP, Chambliss CK, Brooks BW (2018) Differential uptake of and sensitivity to diphenhydramine in embryonic and larval zebrafish. Environ Toxicol Chem 37(4):1175-1181

Kteeba SM, El-Adawi HI, El-Rayis OA, El-Ghobashy AE, Schuld JL, Svoboda KR, Guo L (2017) Zinc oxide nanoparticle toxicity in embryonic zebrafish: mitigation with different natural organic matter. Environ Pollut 230:1125-1140

Kudryasheva NS, Tarasova AS (2015) Pollutant toxicity and detoxification by humic substances, mechanisms and quantitative assessment via luminescent biomonitoring. Environ Sci Pollut Res 22:155-167

Lanphere JD, Rogers B, Luth C, Bolster CH, Walke SL (2014) Stability and transport of graphene oxide nanoparticles in groundwater and surface water. Environ Eng Sci 31(7):350-359

Lawrence C (2007) The husbandry of zebrafish (Danio rerio), a review. Aquaculture 269:1-20

Le Ray D, Juvin L, Ryczko D, Dubuc R (2011) Supraspinal control of locomotion: the mesencephalic locomotor region. Prog Brain Res 188:51-70

Li Q, Xie B, Hwang Y, Xu Y (2009) Kinetics of $\mathrm{C}_{60}$ fullerene dispersion in water enhanced by natural organic matter and sunlight. Environ Sci Technol 43(10):3574-3579

Li Y, Miao X, Chen T, Yi X, Wang R, Zhao H, Lee SM-Y, Wang X, Zheng Y (2017) Zebrafish as a visual and dynamic model to study the transport of nanosized drug delivery systems across the biological barriers. Colloids Surf B: Biointerfaces 156:227-235

Lia P, Xua T, Wua S, Leia L, Hea D (2017) Chronic exposure to graphene-based nanomaterials induces behavioral deficits and neural damage in Caenorhabditis elegans. J Appl Toxicol 37(10):1140 1150. https://doi.org/10.1002/jat.3468

Lin S, Zhao Y, Nel AE, Lin S (2013) Zebrafish: an in vivo model for nano EHS studies. Small 27(9-10):1608-1618

Liu X, Zhang Q, Li S, Chen D, Zhao X, Feng X (2018) Developmental toxicity and neurotoxicity of synthetic organic insecticides in zebrafish (Danio rerio): a comparative study of deltamethrin, acephate, and thiamethoxam. Chemosphere 199:16-25

Livak KJ, Schmittgen TD (2001) Analysis of relative gene expression data using real-time quantitative PCR and the 2(-Delta Delta C(T)) method. Methods 25(4):402-408

Lu L, Wang J, Chen B (2018) Adsorption and desorption of phthalic acid esters on graphene oxide and reduced graphene oxide as affected by humic acid. Environ Pollut 232:505-513

Markovic M, Kumar A, Andjelkovic I, Lath S, Kirby JK, Losic D, Batley GE, McLaughlin MJ (2018) Ecotoxicology of manufactured graphene oxide nanomaterials and derivation of preliminary guideline values for freshwater environments. Environ Toxicol Chem 37(5):1340-1348

McCurley AT, Callard GV (2008) Characterization of housekeeping genes in zebrafish, male-female differences and effects of tissue type, developmental stage and chemical treatment. BMC Mol Biol 9:102

Mendonça MCP, Soares ES, Jesus MB, Ceragioli HJ, Ferreira MS, Catharino RR, Hofling MA (2015) Reduced graphene oxide induces transient blood-brain barrier opening, an in vivo study. Nanobiotechnol 13:78

Menelaou E, Udvadia AJ, Tanguay RL, Svoboda KR (2014) Activation of $\alpha 2 \mathrm{~A}$-containing nicotinic acetylcholine receptors mediates nicotine-induced motor output in embryonic zebrafish. Eur J Neurosci 40(1):2225-2240

Meshalkina DA, Kizlyk MN, Kysil EV, Collier AD, Echevarria DJ, Abreu MS, Barcellos LJG, Song C, Kalueff AV (2017) Understanding zebrafish cognition. Behav Process 141:229-241

Mottier A, Mouchet F, Pinelli E, Gauthier L, Flahaut E (2017) Environmental impact of engineered carbon nanoparticles: from releases to effects on the aquatic biota. Curr Opin Biotechnol 46:1-6

OECD (2000) Guidance Document on Aquatic Toxicity Testing of Difficult Substances and Mixtures. OECD Series on Testing and 
Assessment Number 23. Guidance document on aquatic toxicity testing of difficult substances and mixtures. Organization for Economic Co-Operation and Development, Paris. $53 \mathrm{p}$

OECD (2013) Test Guideline 236. Fish embryo acute toxicity (FET) test. https://doi.org/10.1787/9789264203709-en

Oh B, Lee Y, Fu M, Lee CH (2017) Computational analysis on downregulated images of macrophage scavenger receptor. Pharm Res 34(10):2066-2074

Ong KJ, MacCormack TJ, Clark RJ, Ede JD, Ortega VA, Felix LC, Dang MKM, Ma G, Fenniri H, Veinot JGC, Goss GG (2014) Widespread nanoparticle-assay interference: implications for nanotoxicity testing. PLoS One 9:e90650

Ozkan A, Sen HM, Sehitoglu I, Alacam H, Guven M, Aras AB, Akman T, Silan C, Cosar M, Karaman HI (2015) Neuroprotective effect of humic acid on focal cerebral ischemia injury: an experimental study in rats. Inflammation 38(1):32-39. https://doi.org/10.1007/s10753014-0005-0

Paatero I, Casals E, Niemi R, Özliseli E, Rosenholm JM, Sahlgren C (2017) Analyses in zebrafish embryos reveal that nanotoxicity profiles are dependent on surface functionalization controlled penetrance of biological membranes. Sci Rep 7:8423. https://doi.org/ 10.1038/s41598-017-09312-z

Park MVDZ, Bleeker EAJ, Brand W, Cassee FR, van Elk M, Gosens I, De Jong WH, Meesters JAJ, Peijnenburg WJGM, Quik JTK, Vandebriel RJ, Sips AJAM (2017) Considerations for safe innovation: the case of graphene. ACS Nano 11(10):9574-9593

Pecoraro R, D'Angelo D, Filice S, Scalese S, Capparucci F, Marino F, Iaria C, Guerriero G, Tibullo D, Salvaggio A, Nicotera I, Brundo MV (2018) Toxicity evaluation of graphene oxide and titania loaded nafion membranes in zebrafish. Front Physiol 8:1039

Peijnenburg WJGM, Baalousha M, Chen J, Chaudry Q, Von der Kammer F, Kuhlbusch TAJ, Lead J, Nickel C, Quik JTK, Renker M, Wang Z, Koelmans AA (2015) A review of the properties and processes determining the fate of engineered nanomaterials in the aquatic environment. Crit Rev Environ Sci Technol 45(19):2084-2134

Pelka KE, Henn K, Keck A, Sapel B, Braunbeck T (2017) Size does matter- determination of the critical molecular size for the uptake of chemicals across the chorion of zebrafish (Danio rerio) embryos. Aquat Toxicol 185:1-10

Peng WH, Lee YC, Chau YP, Lu KS, Kung HN (2015) Short-term exposure of zebrafish embryos to arecoline leads to retarded growth, motor impairment, and somite muscle fiber changes. Zebrafish 12(1):59-70

Pereira VM, Bortolotto JW, Kist LW, Azevedo MB, Fritsch RS, da L OR, Pereira TC, Bonan CD, Vianna MR, Bogo MR (2012) Endosulfan exposure inhibits brain $\mathrm{AChE}$ activity and impairs swimming performance in adult zebrafish (Danio rerio). Neurotoxicol 33:469 475. https://doi.org/10.1016/j.neuro.2012.03.005

Pradhan S, Hedberg J, Rosenquist J, Jonsson CM, Wold S, Blomberg E, Odnevall Wallinder I (2018) Influence of humic acid and dihydroxy benzoic acid on the agglomeration, adsorption, sedimentation and dissolution of copper, manganese, aluminum and silica nanoparticles - a tentative exposure scenario. PLoS One 13(2):e0192553

Qiang L, Cheng J, Yi J, Rotchell JM, Zhu X, Zhou J (2016) Environmental concentration of carbamazepine accelerates fish embryonic development and disturbs larvae behavior. Ecotoxicol 25: 1426-1437

Reimer MM, Norris A, Ohnmacht J, Patani R, Zhong Z, Dias TB, Kuscha V, Scott AL, Chen YC, Rozov S, Frazer SL, Wyatt C, Higashijima S, Patton EE, Panula P, Chandran S, Becker T, Becker C (2013) Dopamine from the brain promotes spinal motor neuron generation during development and adult regeneration. Dev Cell 25(5):478491

Ren C, Hu X, Li X, Zhou Q (2016) Ultra-trace graphene oxide in a water environment triggers Parkinson's disease-like symptoms and metabolic disturbance in zebrafish larvae. Biomaterials 93:83-94
Rodrigues A, Brito A, Janknecht P, Proença MF, Nogueira R (2009) Quantification of humic acids in surface water: effects of divalent cations, $\mathrm{pH}$, and filtration. J Environ Monit 11:377-382

Schierz A, Benjamin E, Wiesner MR, Bisesi JH, Sabo-Attwood T, Ferguson PL (2014) Fate of single walled carbon nanotubes in wetland ecosystems. Environ Sci: Nano 1:574-583

Schür C, Rist S, Baun A, Mayer P, Hartmann NB, Wagner M (2019) WHEN Fluorescence is not a particle: the tissue translocation of microplastics in Daphnia magna seems an artifact. Environ Toxicol Chem. https://doi.org/10.1002/etc.4436

Shen M, Hai X, Shang Y, Zheng C, Li P, Li Y, Jin W, Li D, Li Y, Zhao J, Lei H, Xiao H, Li Y, Yan G, Cao Z, Bu Q (2019) Insights into aggregation and transport of graphene oxide in aqueous and saturated porous media: complex effects of cations with different molecular weight fractionated natural organic matter. Sci Total Environ 656: 843-851

Smeets WJ, Gonzalez A (2000) Catecholamine systems in the brain of vertebrates, new perspectives through a comparative approach. Brain Res Rev 33:308-379. https://doi.org/10.1016/S01650173(00)00034-5

Soares JC, Pereira TCB, Costa KM, Maraschin T, Bassoc NR, Bogo MR (2017) Developmental neurotoxic effects of graphene oxide exposure in zebrafish larvae (Danio rerio). Colloids Surf B: Biointerfaces 157:335-346

Soreq H, Seidman S (2001) Acetylcholinesterase - new roles for an old actor. Nat Rev Neurosci 2(4):294-302

Souza J, Baretta JF, Santos F, Paino IM, Zucolotto V (2017) Toxicological effects of graphene oxide on adult zebrafish (Danio rerio). Aquat Toxicol 186:11-18

Spencer RG, Butler KD, Aiken GR (2012) Dissolved organic carbon and chromophoric dissolved organic matter properties of rivers in the USA. J Geophys Res 117:G03001

Strungaru S-A, Robea MA, Plavan G, Todirascu-Ciornea E, Ciobica A, Nicoara M (2018) Acute exposure to methylmercury chloride induces fast changes in swimming performance, cognitive processes and oxidative stress of zebrafish (Danio rerio) as reference model for fish community. J Trace Elem Med Biol 47:115-123

Su Y, Yang G, Lu K, Petersen EJ, Mao L (2017) Colloidal properties and stability of aqueous suspensions of few-layer graphene: importance of graphene concentration. Environ Pollut 220:469-477

Tang R, Dodd A, Lai D, McNabb WC, Love DR (2007) Validation of zebrafish (Danio rerio) reference genes for quantitative real-time RT-PCR normalization. Acta Biochim Biophys Sin Shanghai 39(5):384-390

Teixidó E, Piqué E, Gómez-Catalán J, Llobert JM (2013) Assessment of developmental delay in the zebrafish embryo teratogenicity assay. Toxicol in Vitro 27:469-478

Tintignac LA, Brenner H-R, Rüegg MA (2015) Mechanisms regulating neuromuscular junction development and function and causes of muscle wasting. Physiol Rev 95:809-852

USEPA (2002) Methods for measuring the acute toxicity of effluents and receiving waters to freshwater and marine organisms 5 th edn. Washington

Valim Brigante TA, Abe FR, Zuardi AW, Hallak JEC, Crippa JAS, de Oliveira DP (2018) Cannabidiol did not induce teratogenicity or neurotoxicity in exposed zebrafish embryos. Chem Biol Interact 291:81-86

van Pomeren M, Brun NR, Peijnenburg WJGM, Vijver MG (2017) Exploring uptake and biodistribution of polystyrene (nano)particles in zebrafish embryos at different developmental stages. Aquat Toxicol 190:40-45

Wang Z, Zhao J, Li F, Gao D, Xing B (2009) Chemosphere adsorption and inhibition of acetylcholinesterase by different nanoparticles. Chemosphere 77(1):67-73 
Wang H, Adeleye AS, Huang Y, Li F, Keller AA (2015a) Heteroaggregation of nanoparticles with biocolloids and geocolloids. Adv Colloid Interf Sci 226:24-36

Wang ZG, Zhou R, Jiang D, Sing JE, Xu Q, Si J, Chen Y, Zhou X, Gan L, Li JZ, Zhang H, Liu B (2015b) Toxicity of graphene quantum dots in zebrafish embryo. Biomed Environ Sci 28(5):341-351

Wang M, Gao B, Tang D, Sun H, Yin X, Yu C (2018) Effects of temperature on aggregation kinetics of graphene oxide in aqueous solutions. Colloids Surf A Physicochem Eng Asp 538:63-72

Wu L, Liu L, Gao B, Muñoz-Carpena R, Zhang M, Chen H, Zhou Z, Wang H (2013) Aggregation kinetics of graphene oxides in aqueous solutions, experiments, mechanisms, and modeling. Langmuir 29: 15174-15181

Yang K, Wan JM, Zhang S, Zhang Y, Lee ST, Liu Z (2011) In vivo pharmacokinetics, long-term biodistribution and toxicology of PEGylated graphene in mice. ACS Nano 5:516-522. https://doi. org/10.1021/nn1024303
Yang K, Chen B, Zhu X, Xing B (2016) Aggregation adsorption, and morphological transformation of graphene oxide in aqueous solutions containing different metal cations. Environ Sci Technol 50: 11066-11075

Zhang X, Sui MH, Yan X, Huang TD, Yuan Z (2016) Mitigation in the toxicity of graphene oxide nanosheets towards Escherichia coli in the presence of humic acid. Environ Sci Process Impacts 18(6):744 750

Zhang X, Zhou Q, Zou W, Hu X (2017) Molecular mechanisms of developmental toxicity induced by graphene oxide at predicted environmental concentrations. Environ Sci Technol 51:7861-7871

Publisher's note Springer Nature remains neutral with regard to jurisdictional claims in published maps and institutional affiliations. 